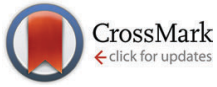

Cite this: Phys. Chem. Chem. Phys., 2016, 18, 31337

DOI: 10.1039/c6cp90261h

www.rsc.org/pccp

\title{
Correction: Benchmark thermochemistry of chloramines, bromamines, and bromochloramines: halogen oxidants stabilized by electron correlation
}

\author{
Daniela Trogolo and J. Samuel Arey* $\dagger$
}

Correction for 'Benchmark thermochemistry of chloramines, bromamines, and bromochloramines: halogen oxidants stabilized by electron correlation' by Daniela Trogolo et al., Phys. Chem. Chem. Phys., 2015, 17, 3584-3598.

Due to an overlooked arithmetic error, our previously published article contains the following erroneous statements. These errors primarily affect the thermochemical data published for $\mathrm{NBr}_{2} \mathrm{Cl}$.

For the last entry of the second column of Table 6, the value 95.21 should be replaced with 71.76 .

For the last entry of the second column of Table 7, the value 91.00 should be replaced with 67.55.

For the last entry of the second column of Table 8, the value 93.46 should be replaced with 70.01 .

In Section 3.4, in the sentence, " $\Delta_{\mathrm{f}} H_{298 K \mathrm{~K} K \text { "BBest” }}^{0, \mathrm{TA14}}$ values range from $12.04 \mathrm{kcal} \mathrm{mol}^{-1}$ to $91.00 \mathrm{kcal} \mathrm{mol}^{-1}$ for chloramines, bromamines and bromochloramines (Table 7).", the value "91.00" should be replaced with "73.82".

In Section 3.5, in the sentence, "Halamine formation is endergonic with respect to the elemental forms at standard state, with

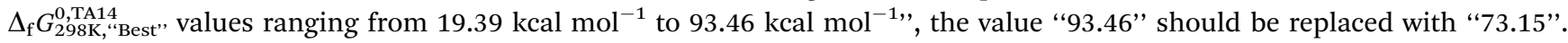

In Section 4, in the sentence, "For comparison, Morris and Isaac ${ }^{9}$ proposed an experimental value of 11.3 for the equilibrium constant, $K_{\mathrm{eq}, \text { aq }}^{\mathrm{Expt}}$, of monochloramine generation in aqueous phase (eqn (21)), derived from the ratio of the experimental forward rate constant, $k_{\mathrm{f}}$, with the experimental reverse rate constant, $k_{\mathrm{r}}$ ", the term " $K_{\text {eq,aq }}^{\text {Ext }}$ " should be replaced with " $\log K_{\text {eq,aq }}^{\text {Expt }}$ ".

These changes do not otherwise affect the conclusions or discussion in the article.

The Royal Society of Chemistry apologises for these errors and any consequent inconvenience to authors and readers. 